\title{
Effective Community Participation In Reconstruction Of Greater Aguata Water Scheme, Enhances Sustainability
}

\author{
Otti, V. I., ${ }^{1}$ Ezenwaji, E. E., ${ }^{2}$ Aginam, H. C. ${ }^{3}$ and Nwafor, A. U. \\ ${ }_{1,4}$ Civil Engineering Department Federal polytechnic, Oko. \\ ${ }^{2}$ Department of Geography and Meteorology Nnamdi Azikiwe University, Awka \\ ${ }^{3}$ Department of Civil Engineering Nnamdi Azikiwe University, Awka
}

\begin{abstract}
The paper focus on the concept of community participation on water scheme without being wholly controlled by the State Water Corporation, rather the communities are empowered to play more active roles in safeguarding and sustaining development programme, emphasising on purpose, decision making, training, operation and maintenance, participation model and benefits, with the aid of SPSS version 21 statistical package. Therefore, the communities are expected to influence and share control over development initiatives, decision and resources that affect them.
\end{abstract}

\section{INTRODUCTION}

The sustainable rural water supply scheme based on community participation is the key focus of Greater Aguata water scheme in partnership with State Water Corporation. The existing dilapidated project is considered for reconstruction and development for an effective community management system which emphasises on maintenance and operation immediately after reconstruction (UNICEF and WHO, 2000). Greater Aguata water project is considered for reconstruction in the year 1998 by the State government through Water Corporation, to boost water supply and reduces sanitation problem, Jacob and Price (2006).

Lockwood (2004) in his operation and maintenance strategies for community managed rural water supply system in Dominican Republic stated that both State government and the local communities should be involved in the responsibility of operation and maintenance of the rural water scheme which yields sustainable results.

The involvement of fourteen communities in Aguata Local government Area will form integral part of the project from the beginning to the end of the reconstruction and the communities in the management role requires decision that can have a major bearing on the ultimate success and sustainability of the project Vergnani (1994).

Rowlands (1995) opined in his empowerment examined development practice that participatory action research on the role of communities in the management of improved rural water supplies involves the understanding of the dynamic and the challenges inherent in the decision making process within the social environment in which the improved water supplies are located. The participation action research will enhance the understanding of the dynamic challenges and constraints of community management (Evans and Appletion, 1993).

The overall community participatory project components include, preparation, community selection, community diagnosis, problem identification, identification of promising solution, experimentation and monitory and evaluation (UNICEF and WHO, 2000).

Kilpatrick (2009), Narayan (1994) and World Bank (1987), observed that community participation is a dynamic process which is in a constant state of change and its assessment includes both qualitative and quantitative aspects, community participation should not base exclusively on the measurement of material, but a useful social effects or processes of development.

IRC 1993 explained the conceptual framework for assessing community participation is based on the flow components of:

- Assessing the understanding of community participation by all stakeholders in the project.

- Assessing the objective of community participation in the project by looking at what is the aim to achieve with community participation.

- Looking at who participates in the project.

- Knowing the intensity and level of community participation

- Establishing the instrument of sustainable community participation.

- Discovering the impact of community participation on the project.

At the Local Government level, the zonal manager from State Water Corporation collaborating with the communities forms a steering committee, which would be responsible for the training of extension workers, planning and supervision of project activities in the communities IRC (1991). 
Obviously beneficial communities would not make a financial contribution, capital cost of the project. They would only provide unskilled labour, and mobilization and provision of locally available materials for construction of water points. After the construction phase the State water corporation takes care of training of pump distribution network and other appurtenance caretakers to be responsible for complex repairs and also monitory of the programme activities in large catchment area on voluntary basis.

\section{AIMS AND OBJECTIVES}

The objectives of community participation are as follow:

- To increase the knowledge and understanding the communities of the concept, process and strategies for enhancing community participation in good government.

- To promote the sense of Government Agency (water corporation) and spirit of engagement for social change among the staff and communities.

- To strengthen the capacity of community representatives to act as change agencies advocates.

- To expose participant to the different areas of community participation in institutional reforms initiative and good governance.

- To build the capacity of staff of Water Corporation and community representative in order to develop and implement action plans.

- To provide a forum experience sharing with successful programme and best practices in community participation in budget and tracking good governance with the staff of the water corporation.

- To ascertain the relationship between the variable and their correlation using SPSS version 21 statistical package.

\section{METHODOLOGY}

\section{Area of study}

Aguata situates in the latitude 6.0167 $\mathrm{N}$ and Longitude 7.0833 $\mathrm{E}$, with a population 370,172 of both adult and children

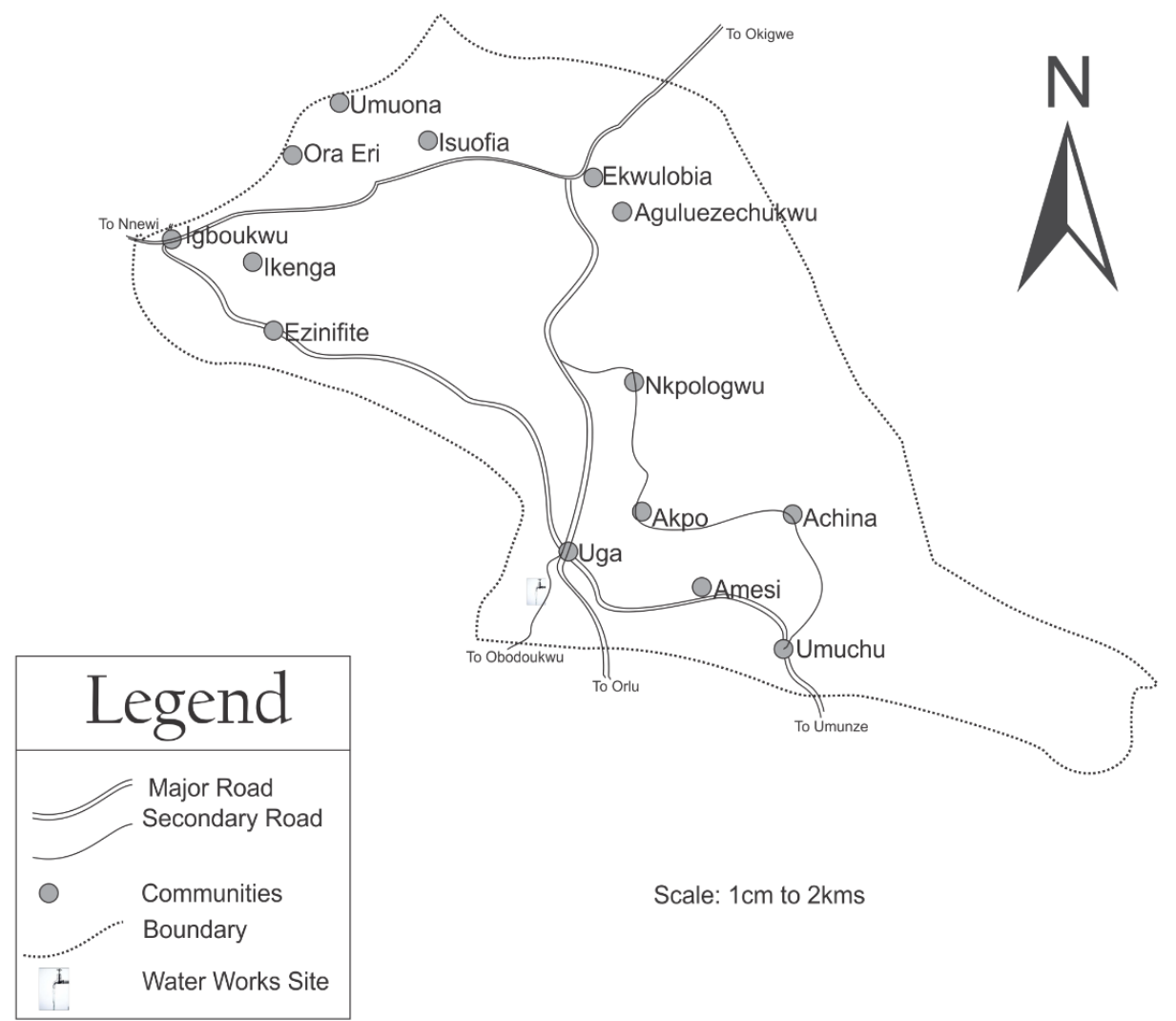

FIG. 1: MAP SHOWING AGUATA L.G.A., ITS COMPONENT COMMUNITIES. 
The State government had in the past solely been responsible for the provision and maintenance of water schemes in the rural area until recently when Anambra State Water Corporation started working in partnership with special focus on women has been on the increase since the State Water Corporation adopted community based management for all rural water schemes to ensure improved and sustainable supply of safe water, which number of projects and pilot-projects were successfully implemented in recent time (Lockwood, 2004). Obviously the prerequisite was to implement the community based management to the standard of the equal quality safe water supply to the communities.

More so, the communities are mobilized and adequately sensitized on project which results in formation of water and health committees Harvey and Skinner (2002).

Among the fourteen communities that made up Aguata Local Government Area only seven communities were allocated with overhead tanks, and the rest are connected through pipe borne-water Rifkin (1986) and IRC (1994),for the reason some communities are over bearing demand (consumption) more than their capacities. Therefore, with the aid of SPSS version 21 statistical package, the solution to the over bearing demand is determined by ascertaining the relationship between the variables (capacity, distance, production, maintenance, consumption and reconstruction (Table 1).

Table l: Communities with overhead tanks and variables

\begin{tabular}{|l|r|r|r|l|r|r|}
\hline Community & $\begin{array}{c}\text { Capacity } \\
\left(\mathbf{M}^{3}\right)\end{array}$ & $\begin{array}{c}\text { Consumption } \\
\left(\mathbf{M}^{3}\right)\end{array}$ & Distance (M) & $\begin{array}{c}\text { Cost of } \\
\text { Reconstruction } \\
(\approx)\end{array}$ & $\begin{array}{c}\text { Cost of } \\
\text { Production } \\
(\approx)\end{array}$ & $\begin{array}{c}\text { Cost } \\
\text { Maintenance } \\
(\approx)\end{array}$ \\
\hline UGA & 100 & 90 & 5 & $6.5 \mathrm{Mm}$ & 450,000 & 290,000 \\
\hline NKOLOGU & 100 & 85 & 10 & $6.5 \mathrm{Mm}$ & 450,000 & 310,000 \\
\hline EKWULOBIA & 100 & 100 & 20 & $6.5 \mathrm{Mm}$ & 450,000 & 350,000 \\
\hline ISUOFIA & 60 & 55 & 25 & $4.5 \mathrm{Mm}$ & 300,000 & 350,000 \\
\hline IGBOUKWU & 45 & 85 & 30 & $3.0 \mathrm{Mm}$ & 250,000 & 350,000 \\
\hline UMUCHU & 45 & 80 & 10 & $3.0 \mathrm{Mm}$ & 250,000 & 310,000 \\
\hline ACHINA & 60 & 55 & 15 & $4.5 \mathrm{Mm}$ & 300,000 & 310,000 \\
\hline
\end{tabular}

\section{ANALYSIS}

In the below table2, the data were collected from Anambra State Water Corporation and were analysed with the aid of SPSS version 21 to establish the relationship between the variables and their correlation. More so, null and alternative hypothesis were used to determine the variable of interest.

With the null hypothesis $\left(\mathrm{H}_{0}\right)$. There is no relationship between the variables of interest, while the alternative hypothesis $\left(\mathrm{H}_{1}\right)$. There is a relationship between the variables of interest.

Observation from Table 2, showed that results of the analysis have strong positive relationship of 0.988 between capacity and cost of construction, 1.00 between capacity and cost of production, while there exist no relationship between capacity and consumption, distance, maintenance.

There is also a strong positive correlation of 0.929 between distance and cost of maintenance. Also cost of production shows a strong positive relationship of 0.984 with cost of construction. Therefore, the correlation was carried out at significant level of $1 \%$ (that is $\alpha=0.012$-tailed). 


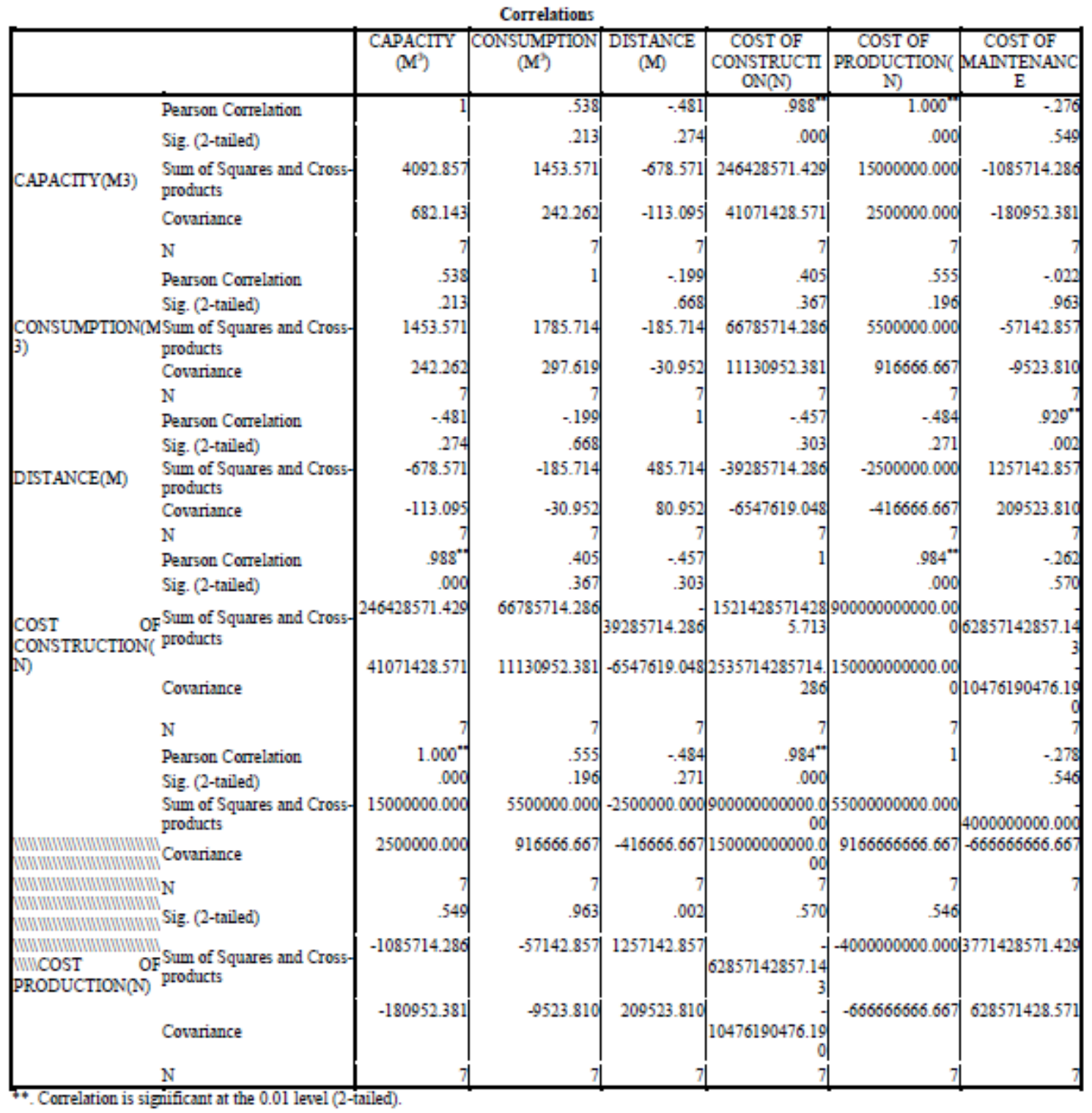

\section{DISCUSSION}

The important of community participation in rural water projects has been widely acknowledge in the millennium development goal of declaration of 2005. It is believed that community participation in its domain will enable communities to contribute towards designing of acceptable and user friendly designs, and makes communities to develop an interest in the operation and maintenance of projects in their areas.

Obviously there is adequate information describing community participation in water projects. However an accurate assessment of community participation has rarely been undertaken in recent time despite the uncertainty with regard to the success of community participation of Oakley 1991 which said participation is stronger in rhetoric than in practical reality, what is therefore required is an in-depth analysis of specific projects in order to find out what went wrong and what lesson could be learned.

More so, community participation is related to empowerment of skills and abilities to enable communities to manage better and to be able to start other development initiative (IRC 1994).

\section{Constraints}

- Sustainability and viability of a good project is dependent on community involvement, which may be undermined by external influence.

- Community participation is an essential component which involves more repairs and maintenance.

- Understanding variety of government approaches which are predominantly technically too much more process oriented. 
- Task to improve project efficiency cost effectiveness or sustainability.

- Time, financial and skill constraints.

\section{RECOMMENDATION}

These are the recommendations to the communities to be involved in

- Formation of water committee.

- Adoption of constitution.

- Election of committee members.

- Application of article of memorandum of understanding between government and communities.

- Selection of project and training agent.

- Input into feasibility study.

- Knowing the labour-rates for skilled and non-skilled workers.

- Community cash contribution rate should be in the emergency fund.

- Selection of skilled labour (Book keepers) Store keeper and supervisors.

- Approval of designs and implementation plan (i.e. technology choice, pipe layout).

- Hiring unskilled labour, composition and rotation of work teams.

- Selection of supplier and contractors.

- Expenditure decision.

- Monitoring progress against budgetary expenditure, operation and maintenance arrangement including tariff rate.

\section{Benefits}

- Ensures the needs and concerns of the people are met.

- Promotes accountability and transparency.

- Accelerates the pace of sustainable development.

- Reduces reckless and wasteful spending.

- Promotes good governance.

- Ensures prompt implementation and completion of projects.

\section{CONCLUSION}

The State government after carefully examination of communities involving in the decision making, consequently that:

- Beneficiaries are happy and feel that they are part of the process, enhance sustainability.

- Ensure self-reliance and increases people sense of control over their issues.

- Wider coverage of intervention programme as more people are influenced by development projects.

- Resources are easily pooled to facilitate project implementation.

- Elevates the status of women since they have the opportunity to be actively involved in programmes.

- The community development is about local democracy that creates the environment for the free contest of competing ideals and interests.

- Identification of community development as an inseparable part of the society which has aims and objectives in fostering spirit of love and patriotism of their home town's welfare, progress and development.

\section{REFERENCE}

[1] Evans, P. and Appleton, (1993). Community management: The role of community in the management of improved water supply systems. The Hague IWSC.

[2] Harvey, P. A. and Skimmer, B.A. (2002). Sustainable borehole projects in Africa Reports from field experience. Leicestershire WEDC.

[3] IRC, (1991). Partners for progress: An approach to sustainable pipe water supplies, technical paper series No. 28, The Hague, The Netherlands.

[4] IRC, (1993). Community management today - The role of communities in management of improved water supply systems: occasional papers 20 . The Hague, The Netherlands.

[5] IRC, (1994). The role of communities in the management of improved rural water supplies in developing countries, participatory field research and the development of strategic methods and tools - an inception report: The Hague, IRC.

[6] Jacob, B. and Prince, N. (2006). Improving access for poorest to public sector health services: Insights from Kirivong operational Health District in Cambodia: Health Policy and Planning 21(1) 27-39.

[7] Kilpatrick, S. (2009). Multi-level rural community engagement in health. The Australian Journal of Rural Health $17,39-44$. 
[8] Lockwood, H. (2004). Operation and maintenance strategies for community managed rural water supply systems. In the Dominican Republic, Environmental Health Project. Activity report No. 105 pp 35.

[9] Narayan, D. (1994). Contribution of people's participation: Evidence from 121 rural water supply projects. Environmentally sustainable development occasional Paper series,

[10] World Bank, Washington DC, pp. $21-28$.

[11] Oakley, P. (1991). Projects with people. The practice of participation in rural development. International labour office, Geneva.

[12] Rifkin, S. B. (1986). Lessons from community participation in health programmes, Health Policy and Planning, Vol. 1, pp 240 - 249.

[13] Rowlands, J. (1995). Empowerment examined development in practice 5(2), 101 - 107.

[14] UNICEF and WHO (2006). Joint monitoring programme definitions of indication http://www.unicef.org $1^{\text {st }}$ September 2006. Pp $19-21$.

[15] Vergnani, L. (1994). Starting a Rural Revolution; Leading Edge. Pp 3 - 9.

[16] World Bank, (1987). Community participation in development projects, Washington DC. 